\title{
A multi-disciplinary training programme for end-of-life care: a sequential simulation
}

SM Weldon' ${ }^{1}$, M Kronfli ${ }^{2}$, A Weil ${ }^{3}$, B Watkins², S Cox ${ }^{3}$, F Bello², R Kneebone ${ }^{2}$

1. University of Greenwich/Barts Health NHS Trust, London, UK

2. Imperial College London, London, UK

3. Chelsea and Westminster Hospital, London, UK

\section{Background/Context/Aims}

Sequential Simulation, ${ }^{1}$ a longitudinal form of simulation, was identified as an effective training approach for multi-disciplinary teams in identifying and caring for patients in their last year of life in a hospital setting. Sequential Simulation is a physical simulation of a pathway of care rather than isolated components of the trajectory. Endof-life care for patients in hospital has been reported as inadequate in the UK. ${ }^{2}$ The need for this training was identified through the literature and an in-house training needs analysis in conjunction with patients and their families.

\section{Methodology /Education Programme or Project Description}

The Sequential Simulation was designed based on the outcomes of the Training Needs Analysis and in conjunction with clinical staff. The pathway was separated into segments of time (day two and day six), following a patient (speciality specific scenario) over a six-day period (from admission). Seven Sequential Simulations training sessions were conducted over a three-month period. A mixed-methods study was conducted through pre and post questionnaires and video-recordings of the simulation and subsequent debrief. Confidence levels were measured to assess any changes pre and post training programme and open-ended questions allowed for further exploration of the results. Evaluation of the training was also conducted.

\section{Results/Outcomes}

14 multi-disciplinary teams consisting of 57 participants in total attended the training: Doctors 45\% (Consultants 26\%, registrars 19\%), nurses 30\% and therapists $25 \%$. Preliminary results revealed that confidence levels were improved across all professional cohorts. $89 \%$ of participants felt the course met their expectations. $87 \%$ 
would consider recommending the course to colleagues and $80 \%$ felt that the course had an impact on their approach to end of life care.

\section{Conclusions and Recommendations}

Sequential Simulation is a unique approach to end of life care training that takes into account the longitudinal element of a patient's end of life journey. Post-training revealed an increase in healthcare professional's confidence in end of life care. The healthcare professional's evaluation of the course was highly positive. Further studies to assess if this innovative form of end of life simulation training has an effect on actual clinical care are needed.

\section{References}

1. Weldon S-M, Ralhan S, Paice E, Kneebone R, Bello F. Sequential simulation of a patient pathway. The Clinical Teacher 2016. doi:10.1111/tct.12549

2. Office for National Statistics. National Survey of Bereaved People (VOICES) 2015. https://www.ons.gov.uk/peoplepopulationandcommunity/healthandsocial care/healthcaresystem/bulletins/nationalsurveyofbereavedpeoplevoices/en gland 2015 